International Journal of Engineering \&Technology, $7(3.12)(2018) 729-733$
SPC
International Journal of Engineering \& Technology
Website: www.sciencepubco.com/index.php/IJET
Research paper

\title{
Monsoon Agriculture - Suggestieve Methods Using Dependable Inflow \& Rainfall for a Command Area
}

\author{
S. Surianarayanan ${ }^{*}$, S. Jaya kumar $^{2}$, S. Jeyaprakash ${ }^{3}$ \\ School of Civil Engineering, SASTRA Deemed University, Thanjavur, Tamil Nadu, India \\ *Corresponding Author Email: ${ }^{1}$ suriyanarayan@ civil.sastra.edu
}

\begin{abstract}
In the recent trend of changing environment, the rainfall and the inflow to the reservoir are getting reduced year by year respectively in agricultural field and in river basins. In this paper the dependable inflow into the reservoir and the rainfall in the command area is estimated with the past 30 years data. The statistical methods and formulae (Variance, Mann- Kendall method) are used to determine the dependable inflow and rainfall for both the monsoons. It is found that the inflow is not dependable for South -West monsoon, to do the agriculture, for a normal crop, with medium water requirement.. For the North - East monsoon both the inflow and rainfall are dependable hence the agriculture can be carried out with a single crop (paddy) having more water requirement (or) possible multi-crops, according to the storage in the reservoir and prediction of rainfall in that season. The deductions for other requirements of the dam, losses for evaporation, conveyance etc has been taken into account. The case study is done with the data for 30 years (1982-2012)for a dam in Tamil Nadu, India.
\end{abstract}

Keywords: Dependable inflow, Dependable rainfall, Variance, Reliability, Mann Kendalltest.

\section{Introduction}

Climatic change is a long term process, the statistical distribution of weather pattern over a period of time range from decades thousands of years[1]. The trend analysis is a method to determine the temporal changes and spatial variations for different parameters according to that climate. According to this, determination of the trend for rainfall and inflow is analysed to known whether the trend is increasing or decreasing for the monsoons [2]. By using the reliability concept plays a major role to analyse and design of water resources system [3] .The non parametric test (Mann - Kendall) and statistical method (Coefficient of variation) are used to determine the rainfall and inflow trends for the monsoons, in this paper.

\section{Study Area and Data Used}

The area of case study is the Sathanur reservoir, constructed during 1985 in Thiruvannamalai district, Tamilnadu, India. It is across the river ponnaiar. It is having the catchment area of 10835 $\mathrm{Km} 2$. The length of the masonry Dam is $418 \mathrm{~m}$ and the length of the earth dam is $362 \mathrm{~m}$. The height of the dam is $45 \mathrm{~m}$ above foundations. The capacity of an reservoir is 229 million $\mathrm{m} 3$ and the live storage capacity is 207 million $\mathrm{m} 3$ the spillway has 9 vents

of $12.2 \mathrm{~m} \mathrm{x} 6.1 \mathrm{~m}$ the capacity of saddle spillway is 2234 $\mathrm{m} 3 / \mathrm{s}$. The length of the river is $7.2 \mathrm{~km}$ up to pick up weir. Period of wet season is September - January and the period of dry season is from December - march. Command area under wet period is 3164 hectare and the crop is paddy. The command area under dry period is 15200 hectare and the crop is groundnut it is having two main canals like LBC (left bank canal), RBC (right bank canal) by this canal the water is supplying for both the seasons. The various feature of the dam are (i) capacity of the reservoir - 340 million cu.m (ii) no of fillings - 20 out of 55 years (iii) annual storage 6796 million cu.m (iv) water spread area -126.6 ha (v) catchment area -87.023 sq.m (vi) area submerged -102.935 ha .The dependable yield available at a site 10.26 cu.m. The new command area 740.57 ha and a old command area was 109.67 ha it contains no of spillway 2 no's. The area reaming after the construction of dam has been increased, additional area of irrigation was achieved I addition to the demand for riparianrights. The 30 years (1982-2012) of rainfall and inflow data are obtained from the damauthorities. 


\section{Methodology}

a) Dependable supply :Compilation of data, calculation of recent 10 years inflow, reducing to water available in field( 0.75 of inflow); Total daily inflow for the inflow within 10 year for a year with medium inflow (dependable).-FOR MONSOON 1,MONSOON2. Periods, 10 days periods in $\mathrm{Mm} 3$ Demand: for each 10 days periods of crop period in $\mathrm{Mm} 3$ using BLANEY-CRIDDLE METHOD., for 2 monsoons.

In this article statistical non parametric estimators are applied i.e coefficient of variation and Mann - Kendall test to determine trends for monsoons according to the 30 years of data .generally Mann - Kendall method most preferable to found out the trend analysis . This formula was derived by both Mann and Kendall. Mann formulated a non- parametric test to deduct trend were Kendall gave the statistic distribution for non - linear trend and turning point.

\subsection{MANN - Kendall Test}

The Mann Kendall formula is given as

$$
\begin{aligned}
& S=\sum_{i=1}^{N-1} \sum_{j=i+1}^{N} \operatorname{sgn}\left(x_{j}-x_{i}\right) \\
& \operatorname{sgn}(x)=\left\{\begin{array}{rr}
+1, & x>0 \\
0, & x=0 \\
-1, & x<0
\end{array}\right. \\
& \mathrm{E}[\mathrm{S}]=\mathrm{O} \\
& \operatorname{Var}[S]=\frac{\left\{n(n-1)(2 n+5)-\sum_{j=1}^{p} t_{j}\left(t_{j}-1\right)\left(2 t_{j}+5\right)\right\}}{18} \\
& Z=\left\{\begin{array}{cc}
\frac{S-1}{[\operatorname{Var}(S)]^{\frac{1}{2}}} & \text { if } S>0 \\
\frac{S+1}{[\operatorname{Var}(S)]^{\frac{1}{2}}} & \text { if } S=0
\end{array}\right.
\end{aligned}
$$

From the above equations the value of $\mathrm{S}$ can calculated by using equation (1), were $n$ is the no of years, $\operatorname{sgn}\left(x_{i}-x_{j}\right)$ it is a difference of each earlier year from each later year. Value follows a standard normal distribution. The positive and negative value of $\mathrm{Z}_{\mathrm{mk}}$ indicates the increasing and decreasing trend. A $95 \%$ confidence level with two tailed $\mathrm{Z}$ value of 1.96.If the $\mathrm{Z}_{\mathrm{mk}}$ value is greater than $\mathrm{z}$ value then the trend is increasing or else it is a no trend.

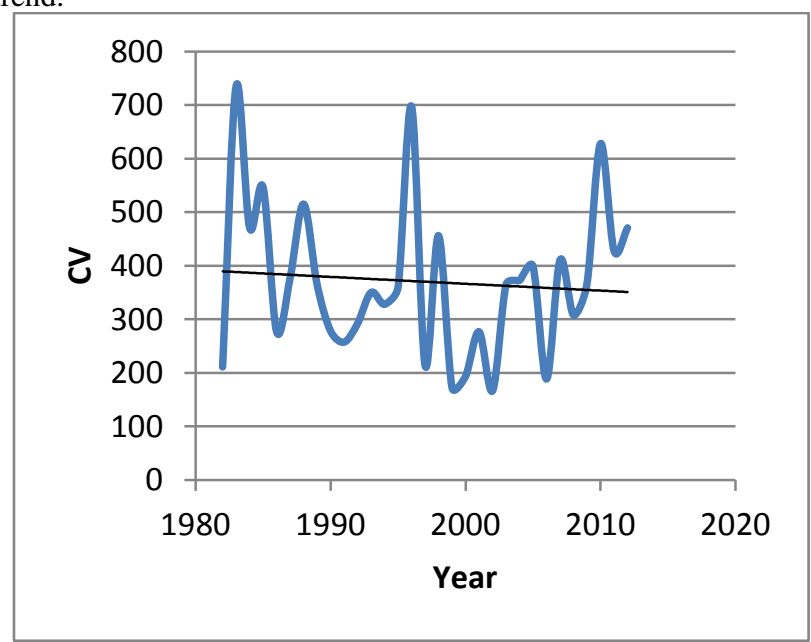

Fig. 3.1.1: Rainfall for monsoon 1 recent 10 years)

Were ' $n$ ' represents the no of years. 


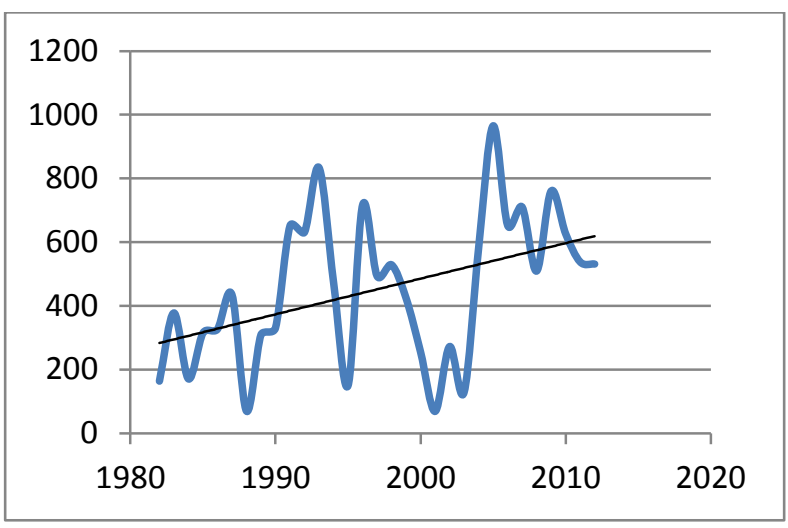

Fig. 3.1.2: Rainfall for monsoon2 --- (recent (1982-2012 rece 10years)
The obtained $\mathrm{z}$ value from Mann Kendall test for monsoon 1 and monsoon 2 was $1.04,2.31$. According to the above rainfall graph it is clearly mentioned that monsoon 1 has no trend and monsoon 2 is an increasing trend. It satisfies the Mann Kendall test.

\subsection{Cofficient of Variation}

The coefficient of variation (cv) is a measure of relative variability. It is the ratio of standard deviation to the mean (average). Then the statistical parameters like mean, standard deviation and $\mathrm{cv}$ is calculated for 30 years of rainfall data.

Table showing the results of statistical calculations for the data

\begin{tabular}{|c|c|c|c|c|c|c|}
\hline Year & Mean & Std.Deviation & C.v & Mean & Std.Deviation & C.v \\
\hline 1982 & 52.75 & 50.76 & 96.23 & 9790 & 57.12 & 139.33 \\
\hline 1983 & 183.75 & 157.02 & 85.45 & 40169 & 115.71 & 122.44 \\
\hline 1984 & 135.75 & 114.26 & 84.17 & 2664.75 & 29.08 & 69.71 \\
\hline 1985 & 136.5 & 38.75 & 28.38 & 6390.75 & 46.15 & 58.60 \\
\hline 1986 & 69.5 & 63.47 & 91.65 & 5304.75 & 42.05 & 51.438 \\
\hline 1987 & 94.25 & 83.77 & 88.89 & 22974.75 & 87.51 & 80.47 \\
\hline 1988 & 128.75 & 113.15 & 87.89 & 1257 & 20.46 & 116.96 \\
\hline 1989 & 91.25 & 75.99 & 183.28 & 16640.69 & 74.47 & 96.25 \\
\hline 1990 & 69.5 & 95.5 & 137.41 & 7264.75 & 49.20 & 59.46 \\
\hline 1991 & 64.32 & 41.94 & 65.21 & 104173.2 & 186.34 & 114.40 \\
\hline 1992 & 73 & 60.51 & 82.83 & 147116.9 & 221.44 & 140.33 \\
\hline 1993 & 87.5 & 45.65 & 52.17 & 96675.03 & 171.51 & 86.10 \\
\hline 1994 & 81.95 & 80.95 & 98.78 & 54596.88 & 134.90 & 113.55 \\
\hline 1995 & 90 & 22.73 & 25.25 & 5277 & 41.94 & 111.84 \\
\hline 1996 & 111.75 & 84.04 & 75.21 & 82042 & 165.37 & 92.38 \\
\hline 1997 & 53.5 & 36.02 & 67.33 & 30931 & 101.53 & 82.21 \\
\hline 1998 & 114 & 76.17 & 66.82 & 33836.75 & 106.20 & 80.34 \\
\hline 1999 & 43 & 42.94 & 99.88 & 35761.72 & 109.18 & 102.90 \\
\hline 2000 & 48.37 & 59.81 & 123.65 & 9592.14 & 56.54 & 88.49 \\
\hline 2001 & 69.15 & 61.82 & 89.40 & 3570.75 & 34.5 & 200 \\
\hline 2002 & 41.62 & 45.02 & 108.16 & 24806.19 & 90.93 & 133.47 \\
\hline 2003 & 91.15 & 109.23 & 119.83 & 5244.75 & 41.81 & 129.64 \\
\hline 2004 & 93.12 & 131.49 & 141.19 & 103567.9 & 185.80 & 127.89 \\
\hline 2005 & 99.6 & 61.97 & 62.22 & 165322.4 & 234.74 & 97.30 \\
\hline 2006 & 47.1 & 41.23 & 87.54 & 96621.98 & 179.46 & 109.91 \\
\hline 2007 & 102.6 & 50.23 & 48.96 & 57697.69 & 138.68 & 78.09 \\
\hline 2008 & 76.87 & 33.73 & 43.87 & 41609.87 & 117.77 & 92.47 \\
\hline 2009 & 91.75 & 129.38 & 141.01 & 71603.19 & 154.49 & 81.24 \\
\hline 2010 & 156.95 & 78.55 & 50.04 & 86623.44 & 169.92 & 108.50 \\
\hline 2011 & 106.95 & 41.35 & 38.66 & 24265.63 & 89.93 & 66.84 \\
\hline 2012 & 117.62 & 75.27 & 63.99 & 43310.11 & 120.15 & 90.44 \\
\hline
\end{tabular}

Mean: $\left(\mathrm{X}_{\mathrm{avg}}\right)=\sum \mathrm{X}_{\mathrm{i}} / \mathrm{n} \quad$ Were $\mathrm{X}_{\mathrm{i}}$ is the rainfall, $\mathrm{n}$ is the no of years.

Standard deviation: $\sigma=\left[\sum\left(\mathrm{X}_{\mathrm{i}}-\mathrm{X}_{\mathrm{avg}}\right)^{2} / \mathrm{n}-1\right]^{1 / 2} \quad$ Were $\mathrm{X}_{\text {avg }}$ is the mean value.

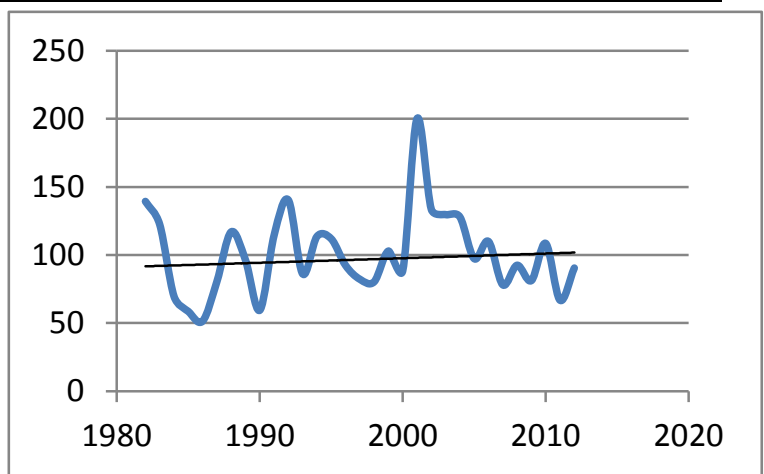

Coefficient of variation: $\mathrm{Cv}=\left(\sigma / \mathrm{X}_{\mathrm{avg}}\right) \times 100$

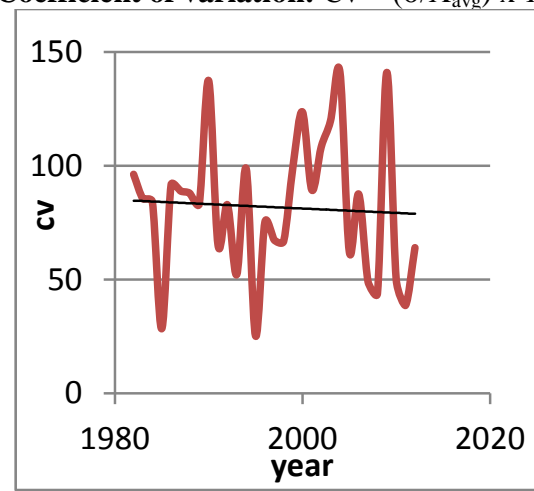

Fig. 3.2.1: c.v for monsoon1(1982-2012-- recent 10 years) 


\begin{tabular}{|l|l|l|l|l|l|l|l|l|}
\hline MONTH & DAYS & ET & $\mathrm{K}_{\mathrm{C}}$ & $\begin{array}{l}\text { ET } \\
\text { CROP }\end{array}$ & ET CROP(m) & AREA & M3 \\
\hline AUGUST & 30 & 7.5 & 1.1 & 247.5 & 0.2475 & 31640000 & 7830900 \\
\hline SEPTEMBER & 15 & 5.6 & 1.1 & 92.4 & 0.0924 & 31640000 & 2923536 & 7.83 \\
\hline SEPTEMBER & 15 & 5.6 & 1.05 & 88.2 & 0.0882 & 31640000 & 2790648 & 2.92 \\
\hline OCTOBER & 30 & 3.8 & 1.05 & 119.7 & 0.1197 & 31640000 & 3787308 \\
\hline NOVEMBER & 20 & 3.8 & 1.05 & 79.8 & 0.0798 & 31640000 & 2524872 \\
\hline NOVEMBER & 10 & 3.3 & 0.95 & 31.35 & 0.03135 & 31640000 & 991914 \\
\hline DECEMBER & 15 & 2.9 & 0.95 & 41.32 & 0.04132 & 31640000 & 1307364 \\
\hline
\end{tabular}

From the above graphs the trend of cv for monsoon 1 has no trend and the monsoon 2 has gradually increasing trend and hence the monsoon 2 is more reliable.

\subsection{Reliability}

Reliability is defined as a measure of how demand is met with supply for a given in a particular period of crop. In this arcticle volumetric releability concept is used to calculate the ratio between supply and demand for various periods of crop-periods in a particular monsoon season of year. The deamand for the food crop (paddy samba) is determined using the standard values of ETo , ETc from the manual preapred by IMTI (Irrigation Management Training Institute ) Trichy,INDIA .The supply is calculated using $75 \%$ of inflow data including the losses for evaporation and conveyance in the same monsoon period of normal inflow within the last 10 years (2002-2012)

\subsection{Demand}

The demand is calculated by using Blaney- criddle formula for Paddy using exact metrological details for the auycat area. In this area the paddy is irrigating from the month august to december for an irrigation area of 3164 hectare (The area of agricuture during

\begin{tabular}{cc}
\hline MONTH & $\begin{array}{l}\text { INFLOW IN Mm3 } \\
\text { (for a medium year) }\end{array}$ \\
\hline August (30days) & 1.155 \\
September (15days) & 2.016 \\
September (15days) & 2.016 \\
October (30days) & 3.024 \\
November (20days) & 69.006 \\
November (10 days) & 42.0045 \\
December (15 days) & 42.1754 \\
\hline
\end{tabular}

wet period commaned by Sathanur dam)
From this calculation the ET having a depth of $0.70027 \mathrm{~m}$ and a total demand for paddy is of $22.15654 \mathrm{Mm} 3$.

\subsection{Supply}

From the normal year of inflow for the past 10 years (2002-2012) the supply of the year is calculated from august to December.

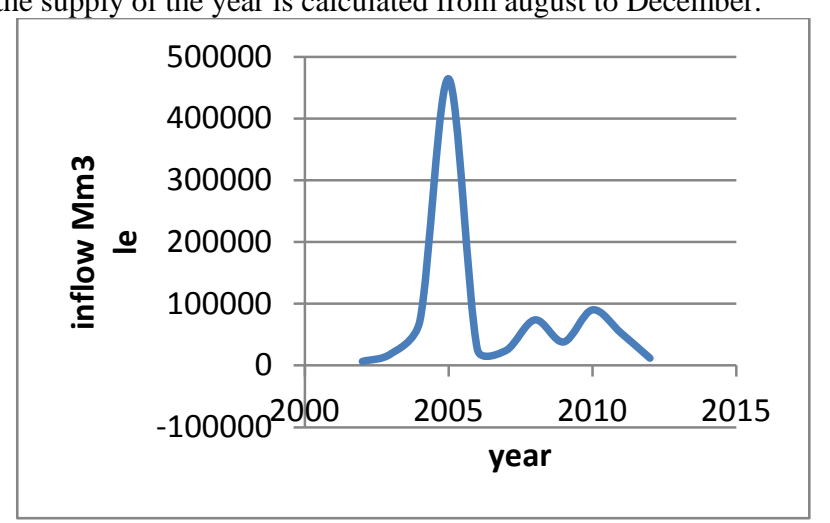

The supply for the particular season of the year is $217.9434 \mathrm{Mm} 3$. Hence the supply is low only at the beginning of the period when compare to the demand. It can manage by using the rainfall and by using the groundwater. And then the next period of agriculture can be done by using the inflow itself. Therefore for the wet period th e paddy agriculture is reliable. 


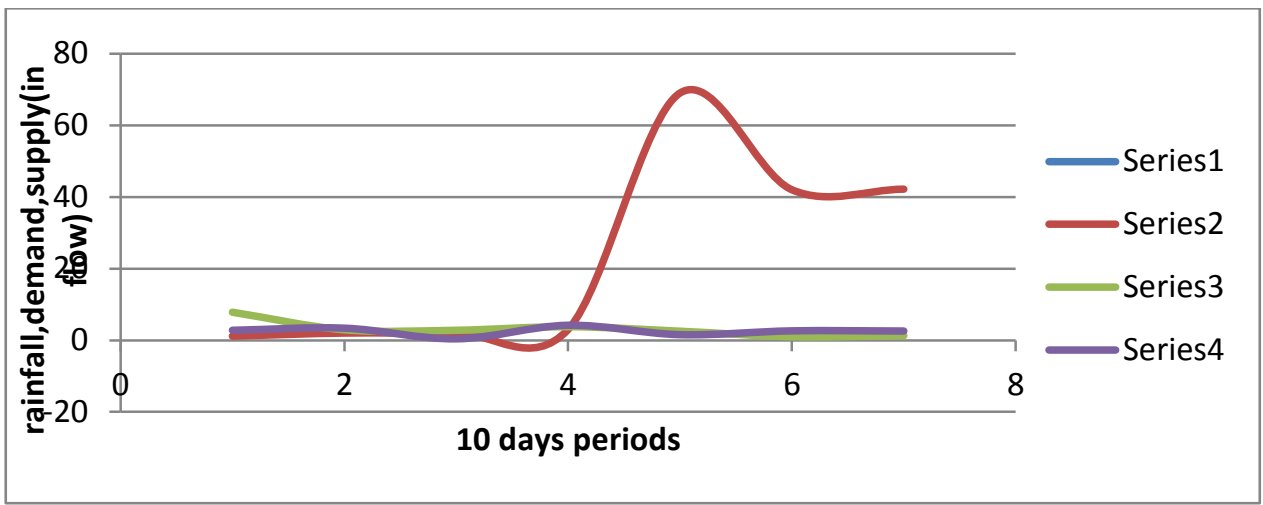

Series 1---Demand, Series 2-supply, Serious3--Rainfall

Fig. 3.5.1: It shows for rainfall, supply and demand for a particular season (aug-dec)

\subsection{Scheduling}

The scheduling of agriculture is done for four phases of crop growth (paddy) is analysed and the volumetric reliability is also calculated for that season.

\begin{tabular}{|c|c|c|c|}
\hline Month & Supply Mm3 & Demand Mm3 & Volumetric reliability(Rv) \\
\hline August (30) & 1.155 & 7.83 & 0.1474 \\
\hline September(15) & 2.016 & 2.925 & 0.7054 \\
\hline September(15) & 2.016 & 3.787 & 2.524 \\
\hline October(30) & 3.024 & 0.9919 & 0.7984 \\
\hline November (20) & 69.006 & 1.307 & 27.33049 \\
\hline November(10) & 42.0045 & 42.34692 & \\
\hline
\end{tabular}

In this table the supply is multiplied by a factor of 0.75 , for all losses including conveyance, evaporation etc. It is found that due to continuous irrigation during crop-period a supply-demand factor of 0.75 will suffice to maintain soil-moisture such that it doesn't go beyond critical level of wilting -point, and will resolve the problem of failure of crop until its full growth. But the Rv is very below 0.75 for the first month which can be tackled by the storage in the pre existing tanks by standard allocations, as per the riparian-rights of the Dam. Also with the high value of Rv for the remaining periods the farmer can suggest to do multi -cropping (or)mixed -cropping with the prediction for a particular year. Hence the volumetric reliability is satisfies for this period of time and the agriculture can be done safe at this period.

\section{Results and Discussion}

From the study of analysis of monsoons, it is found that the agriculture for the monsoon 2 can be carried out successfully for a normal year because the trend flobtained from both the Mann Kendall and co efficient of variation is in increasing trend, for bath inflow and rainfall. For the monsoon 1 there is no trend is obtained from both Mann Kendall and co efficient of variation even for a normal year. Hence the agriculture is not suggestible with for monsoon 1. But that can be managed from the excess inflow water if available in the dam for each particular year after wet season, prediction of rainfall and by using water effective method for agriculture like drip irrigation \& augmentation of water using ground water if available and percolation ponds. If crops other than paddy is taken which can be a used crop-rotation for monsoon 1 will be helpful to get back the nutrients for the soil.
Volumetric reliability, $=\mathrm{V}_{\mathrm{s}} / \mathrm{V}_{\mathrm{d}}$

Were $\mathrm{V}_{\mathrm{s}}$ is the volume of the water supplied.

$\mathrm{V}_{\mathrm{d}}$ is the volume of the water demand during the period of the time.

\section{References}

[1] S. Swain and M. K. Verma. .Statistical trend analysis of monthly rainfall for Raipur District Chhattisgarh. International Journal of Advanced Engineering Research Studies. IV. 87-89

[2] Mohammed J.M Otache Matins Y and JibrilI. Stochastic characteristics of rainfall and river flow of kainji reservoir system. Journal of Environmental Studies. Vol 3. No.2. December 2017

[3] X. Cai, D.C. Mckinney and M.W. Rosegrant.Sustainability analysis for irrigation water management in the Aral Sea region. Agricultural Systems. February 2003

[4] S. Suryanarayanan ,C.R.Suribabu and K. Ramakrishnan. Sustainable irrigation allocation model for dry and wet periods using reservoir storage and inflor. IOP Conference Series: Earth and Environmental Sciences. Volume 80. 2017.

[5] P.P. Majumdarand R. Teegavarapu. A Short-term reservoir operation model for multi-crop irrigation, Hydrological Sciences. Published online December 25, 2009.

[6] P.P. Majumdar and T.S.V. Ramesh. Real-time reservoir operation for irrigation. Water Resources Research. Vol. 33. May 1997

[7] S. Vedula and N. Kumar. An integrated model for optimal reservoir operations for irrigation of multiple crops. Water Resources Research Vol. 32. April 1996

[8] N. Kumar. Optimal irrigation allocation: A multilevel approach. Journal of Irrigation and Drainage Engineering. May 2000. 